\title{
Remarkably Facile Solvolyses of Triflates via Carbocationic Processes in Dimethyl Sulfoxide
}

\author{
Xavier Creary,* and Elizabeth A. Burtch \\ Department of Chemistry and Biochemistry \\ University of Notre Dame \\ Notre Dame, IN 46556
}

Supporting Information

${ }^{1} \mathrm{H}$ and ${ }^{13} \mathrm{C}$ NMR spectra of compounds $\mathbf{1 4}, \mathbf{3 6}, \mathbf{4 5}, \mathbf{4 6}$, and $47 . \quad$ S2-S11

Evolving ${ }^{1} \mathrm{H}$ NMR Spectra During Reaction of Triflate 9 in DMSO- $\mathrm{d}_{6} \quad$ S12

Evolving ${ }^{19}$ F NMR Spectra During Reaction of Triflate 33 in DMSO-d $d_{6} \quad$ S13 
<smiles>IC1(I)CC1</smiles> 


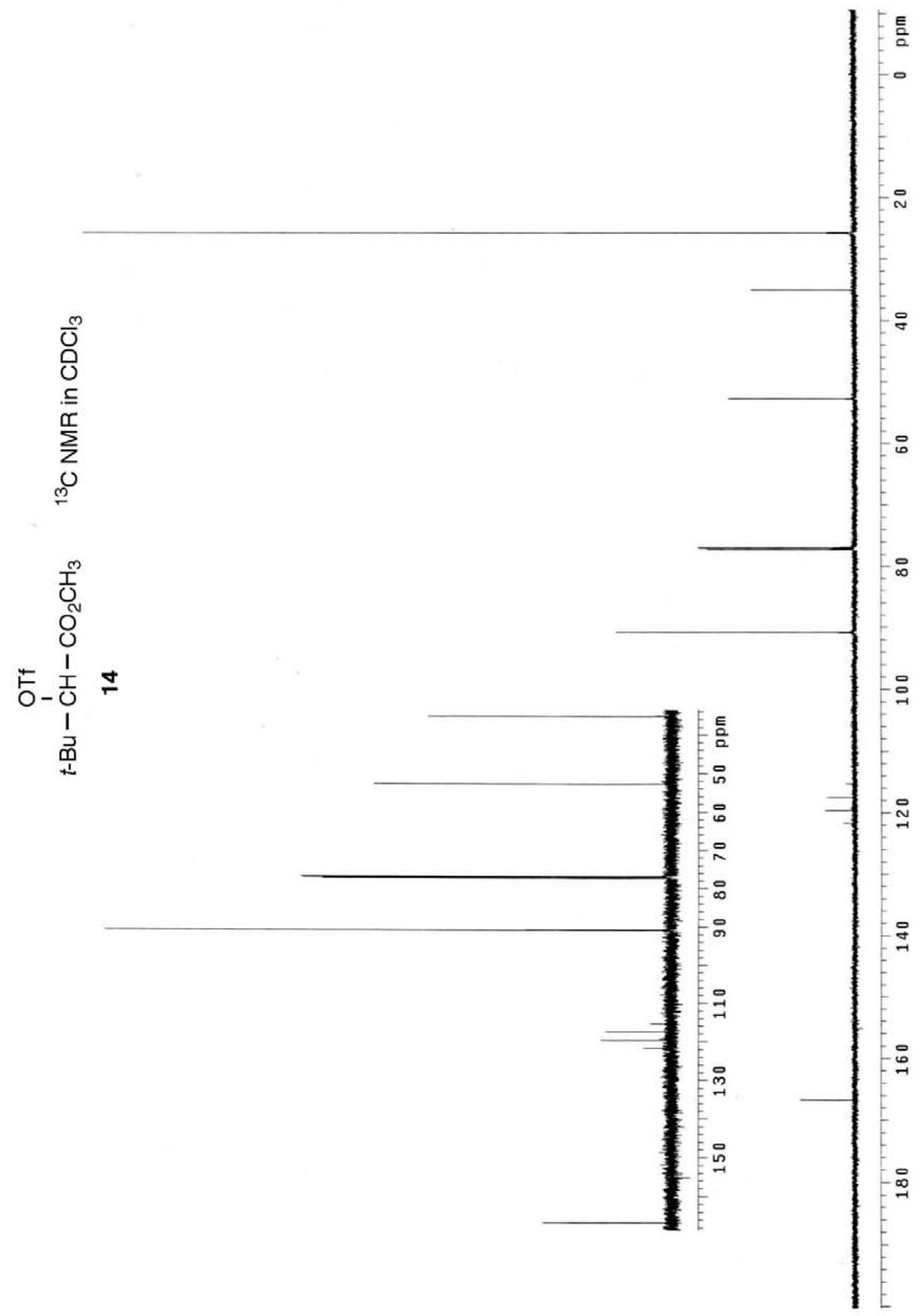




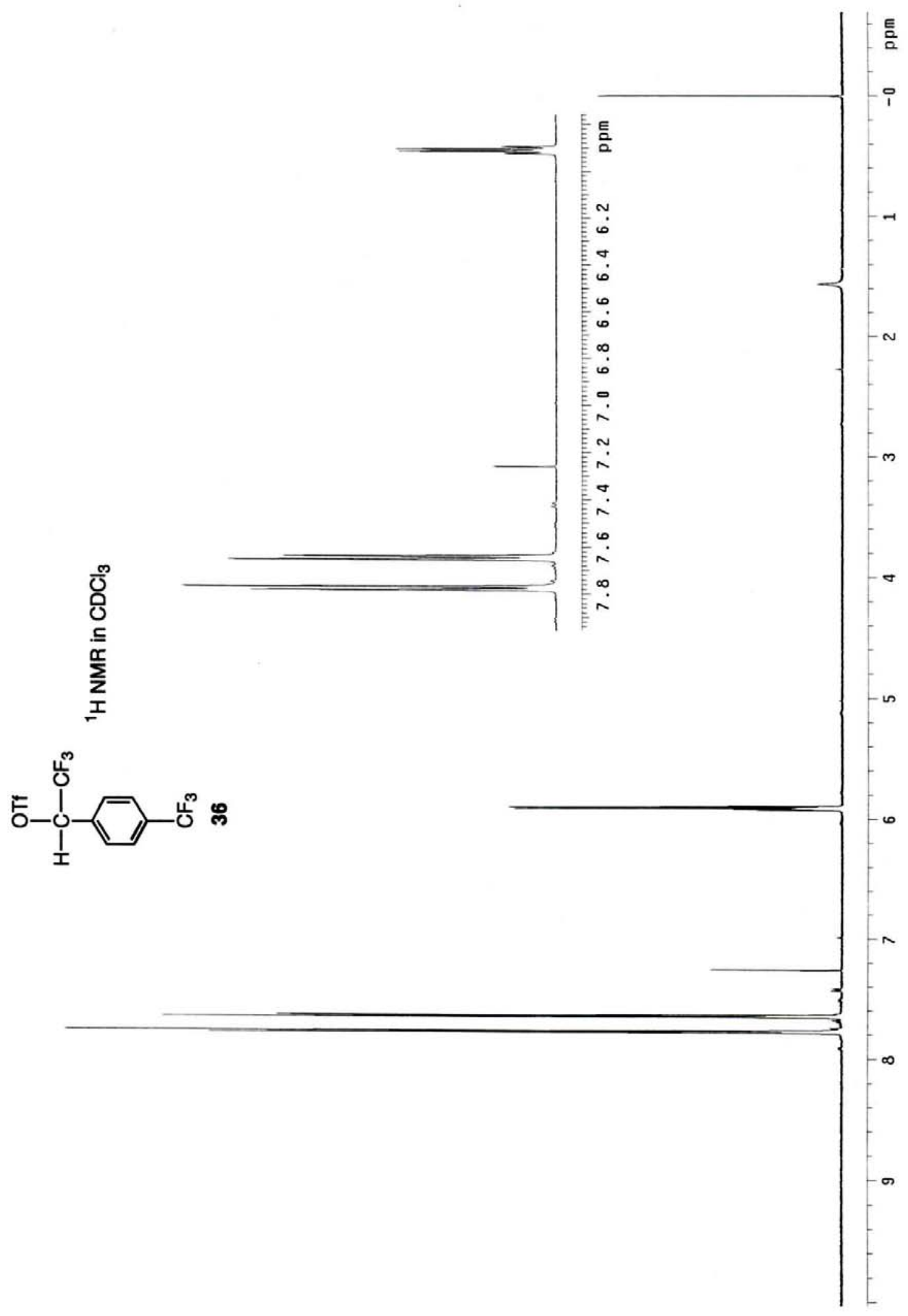




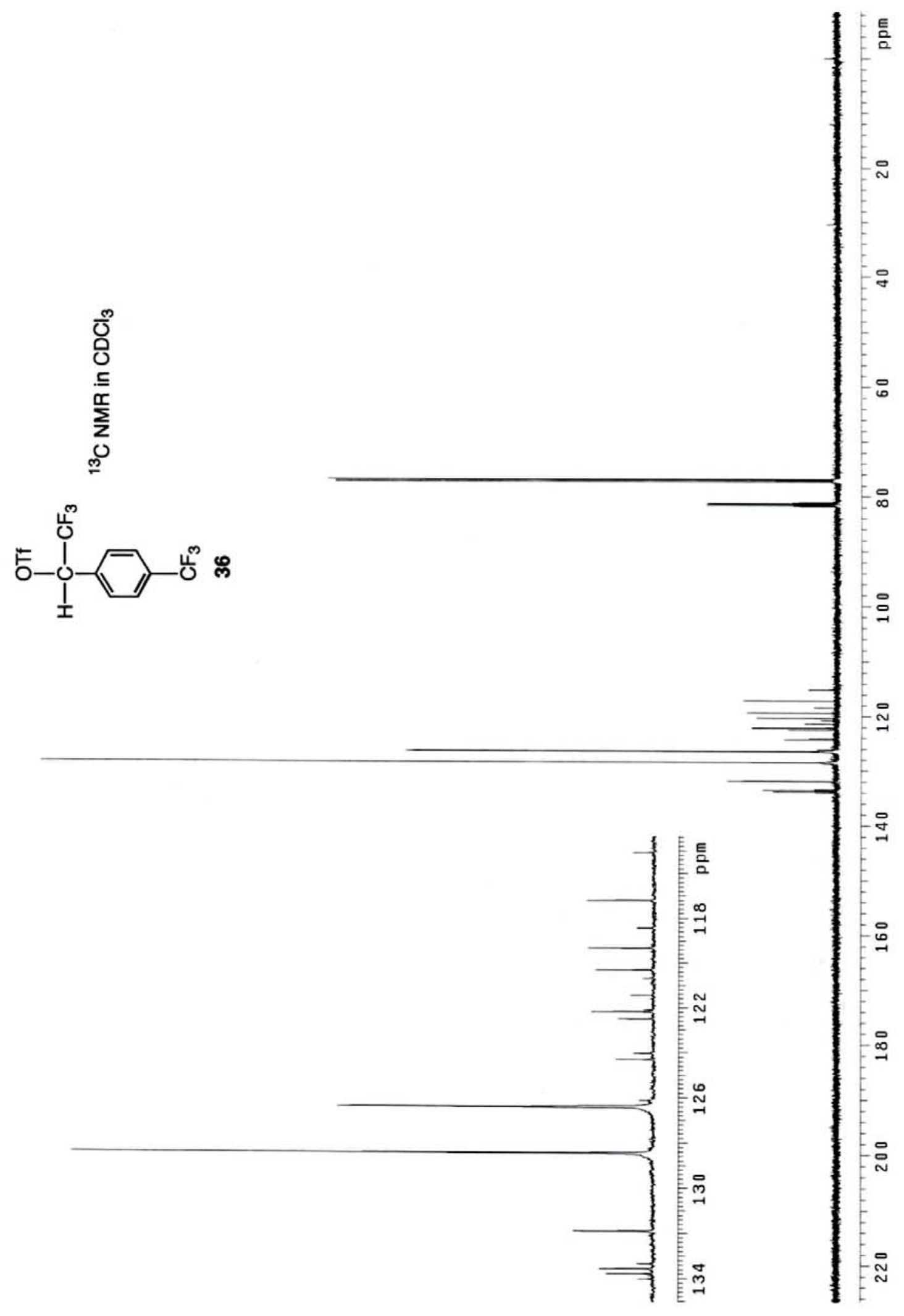




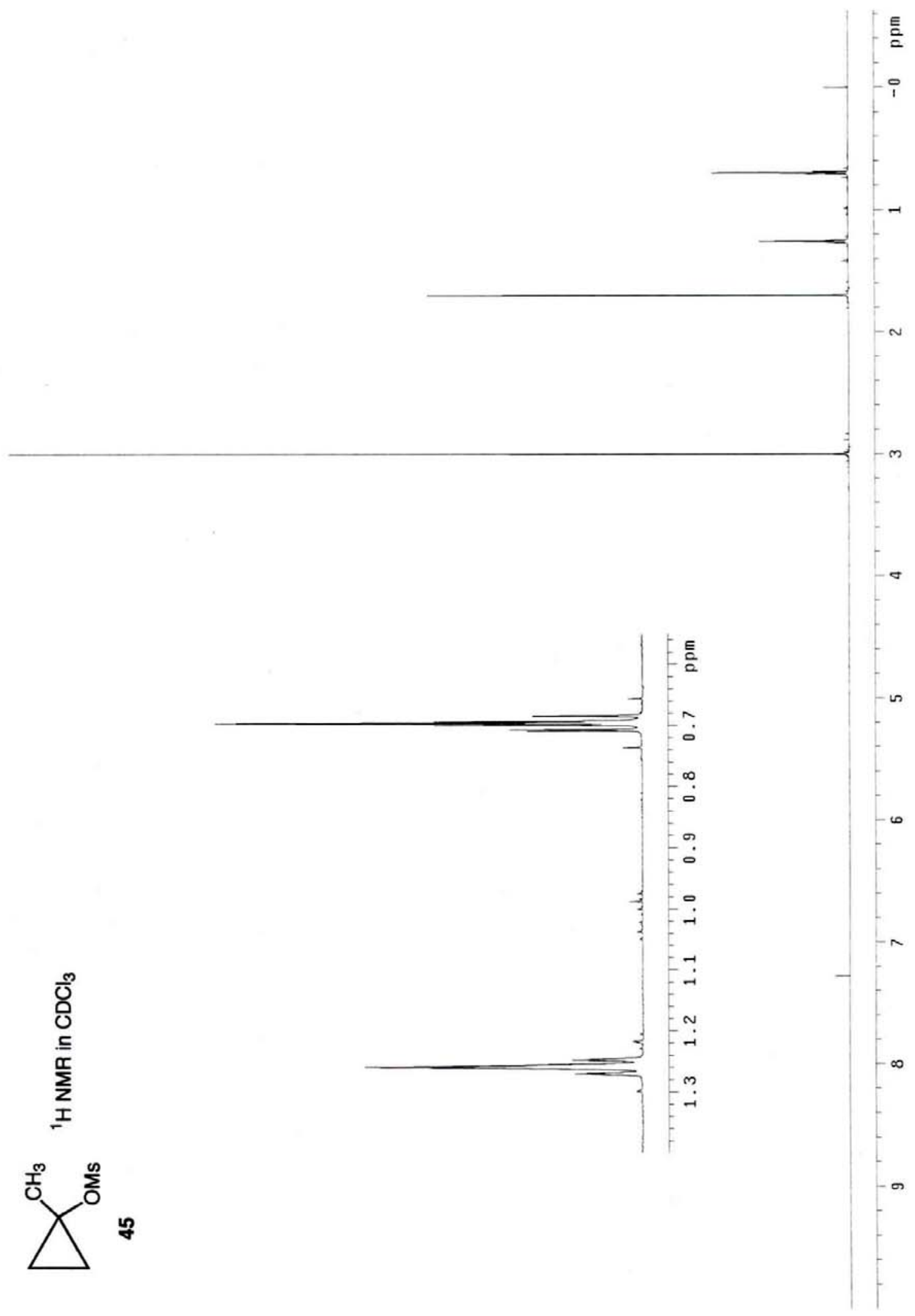




$$
i
$$




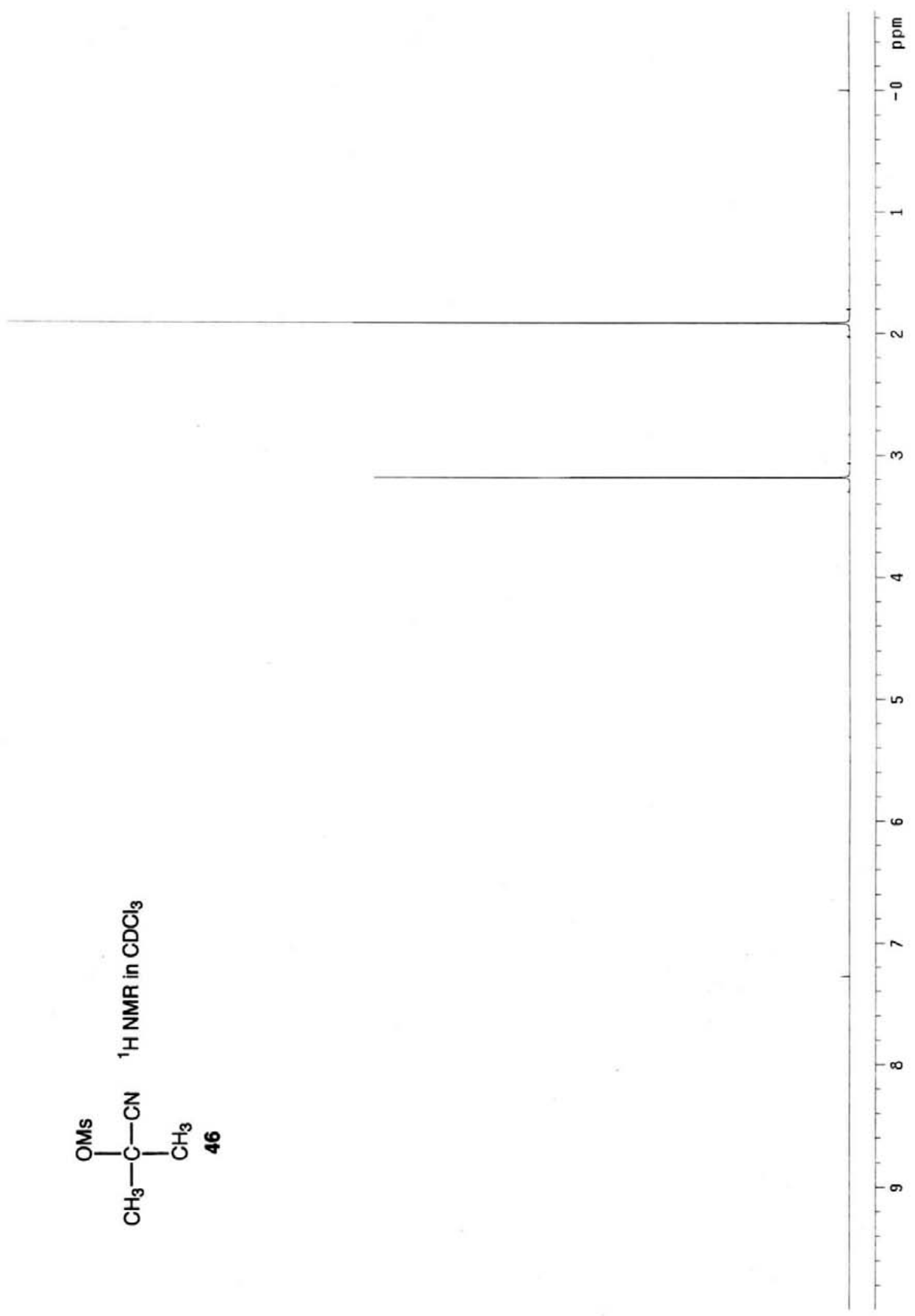




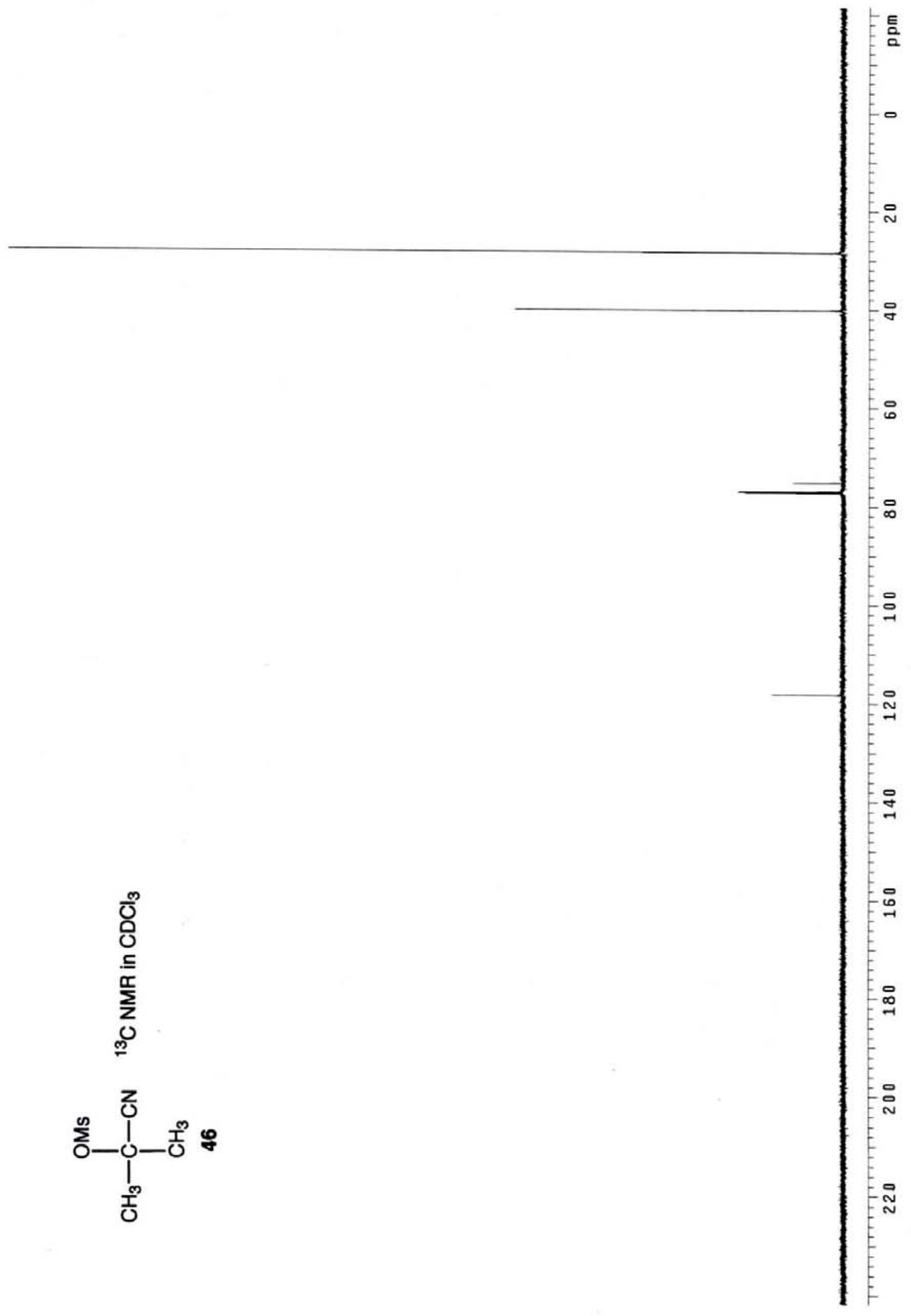




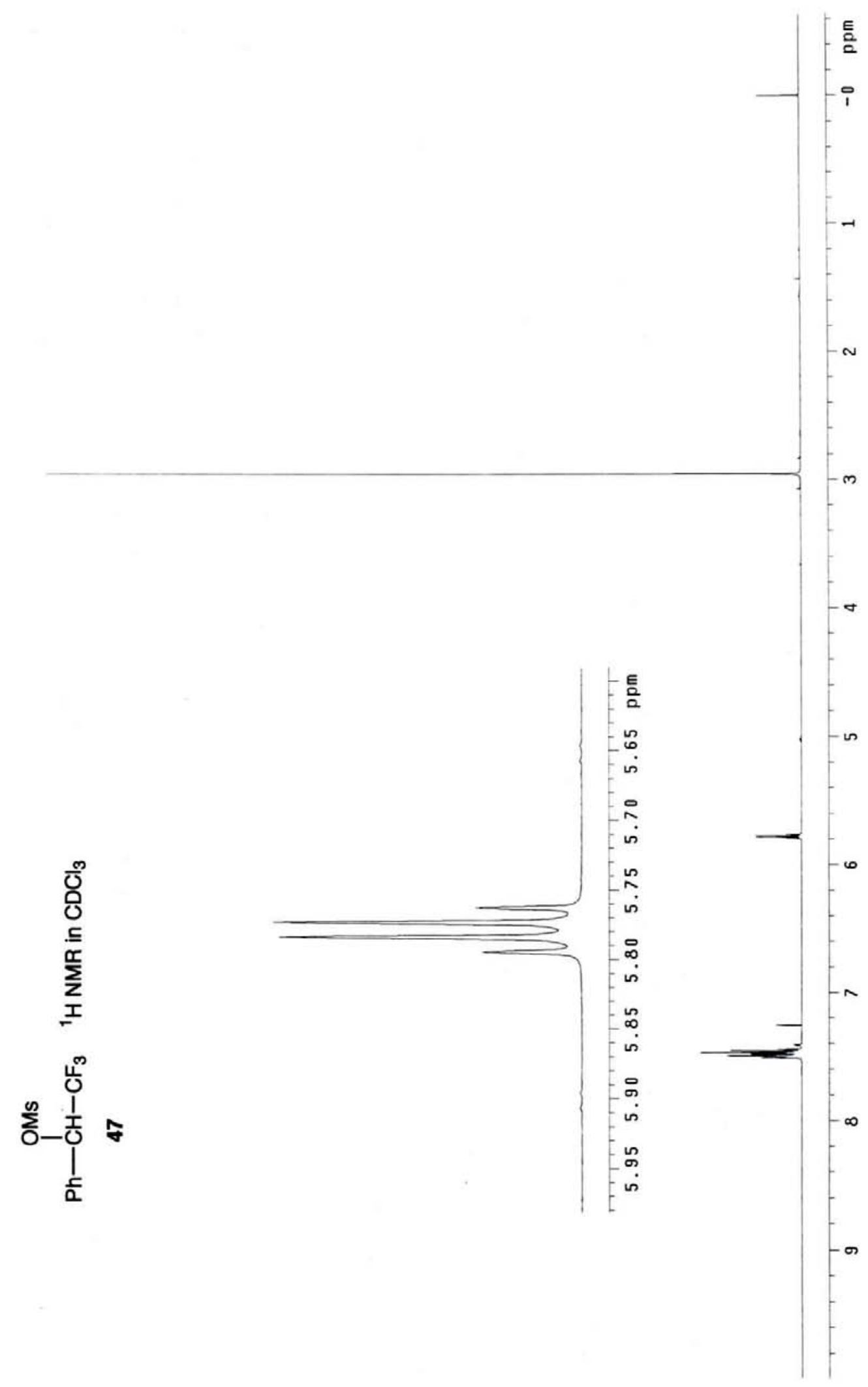


S11

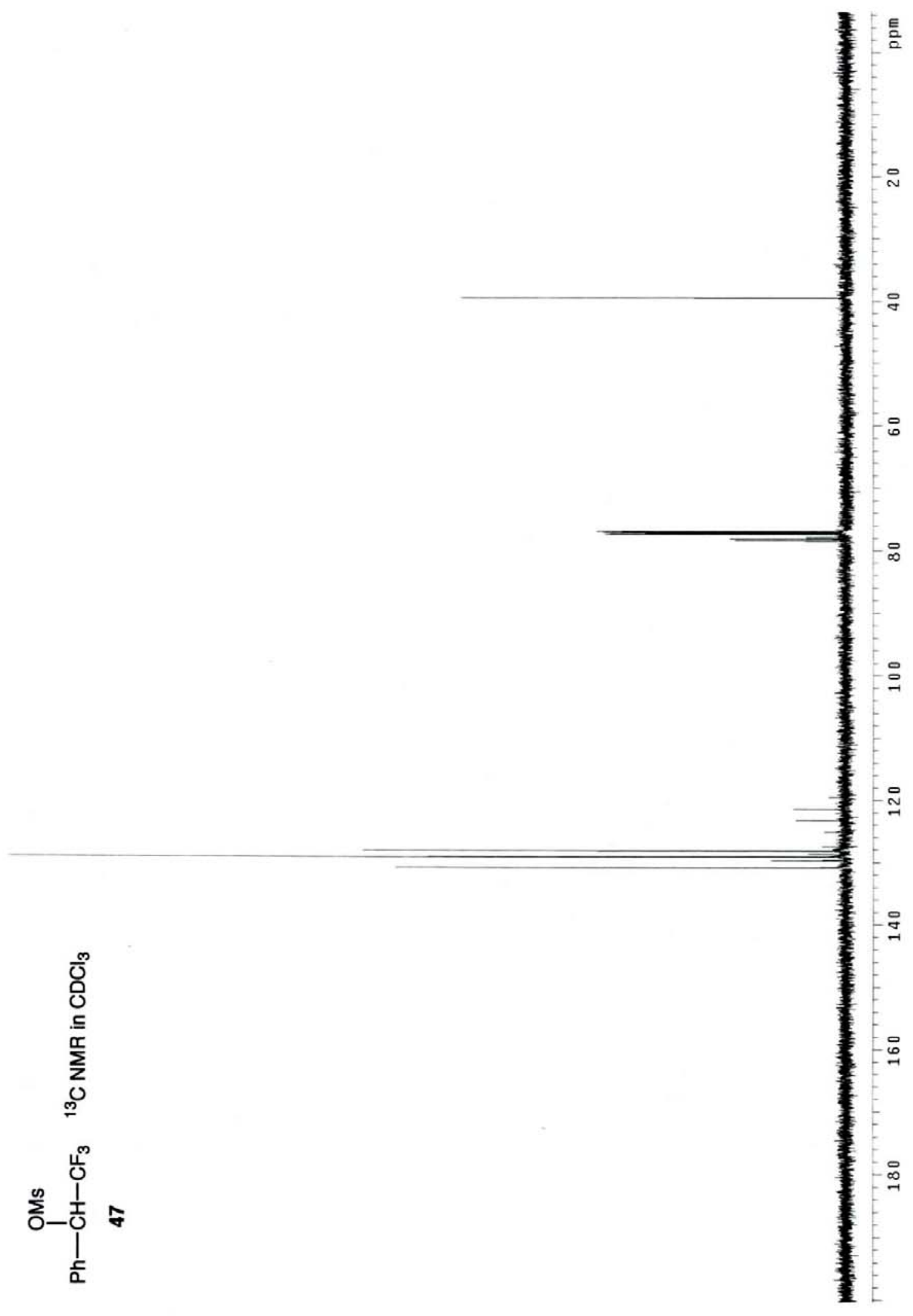


S12
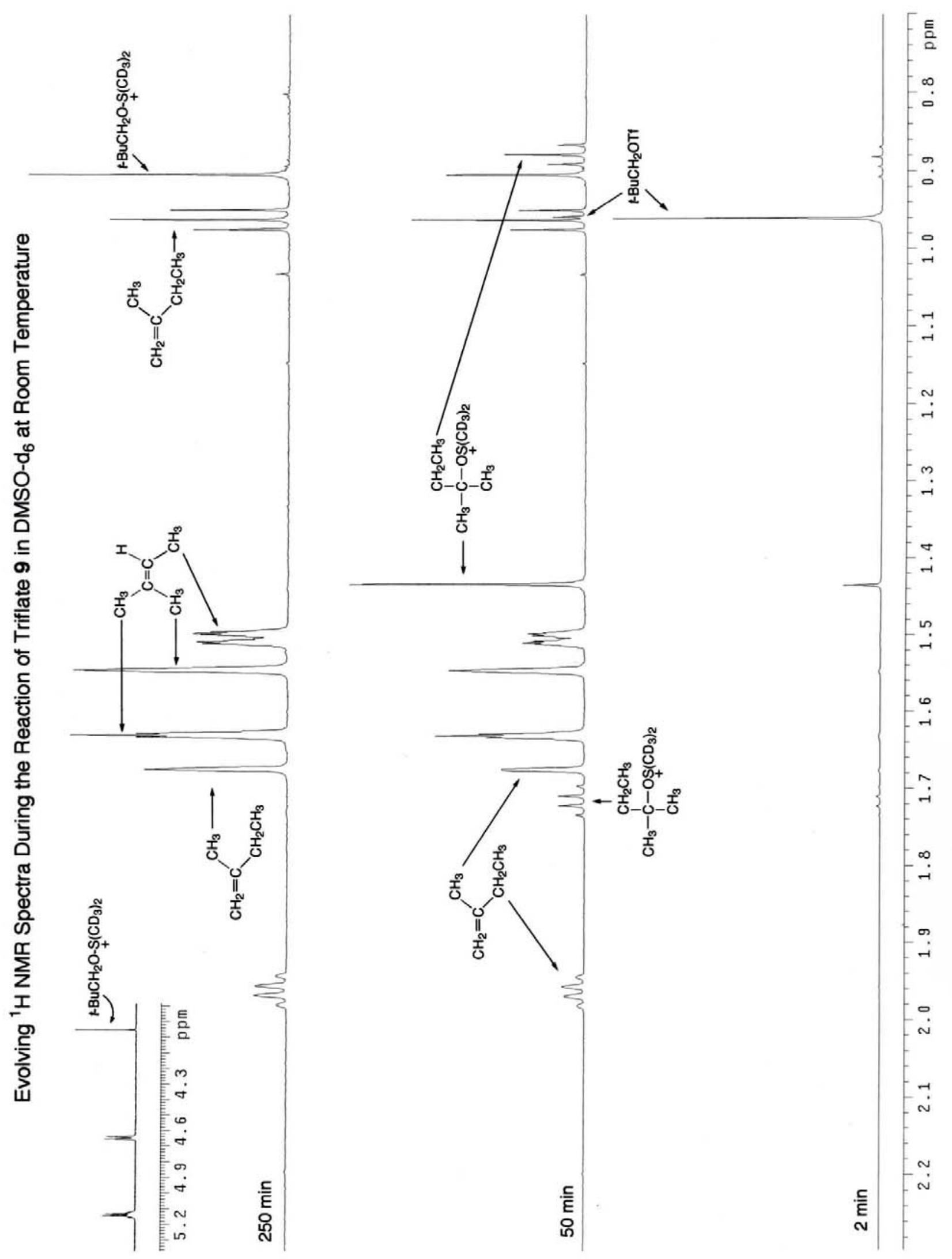
S13

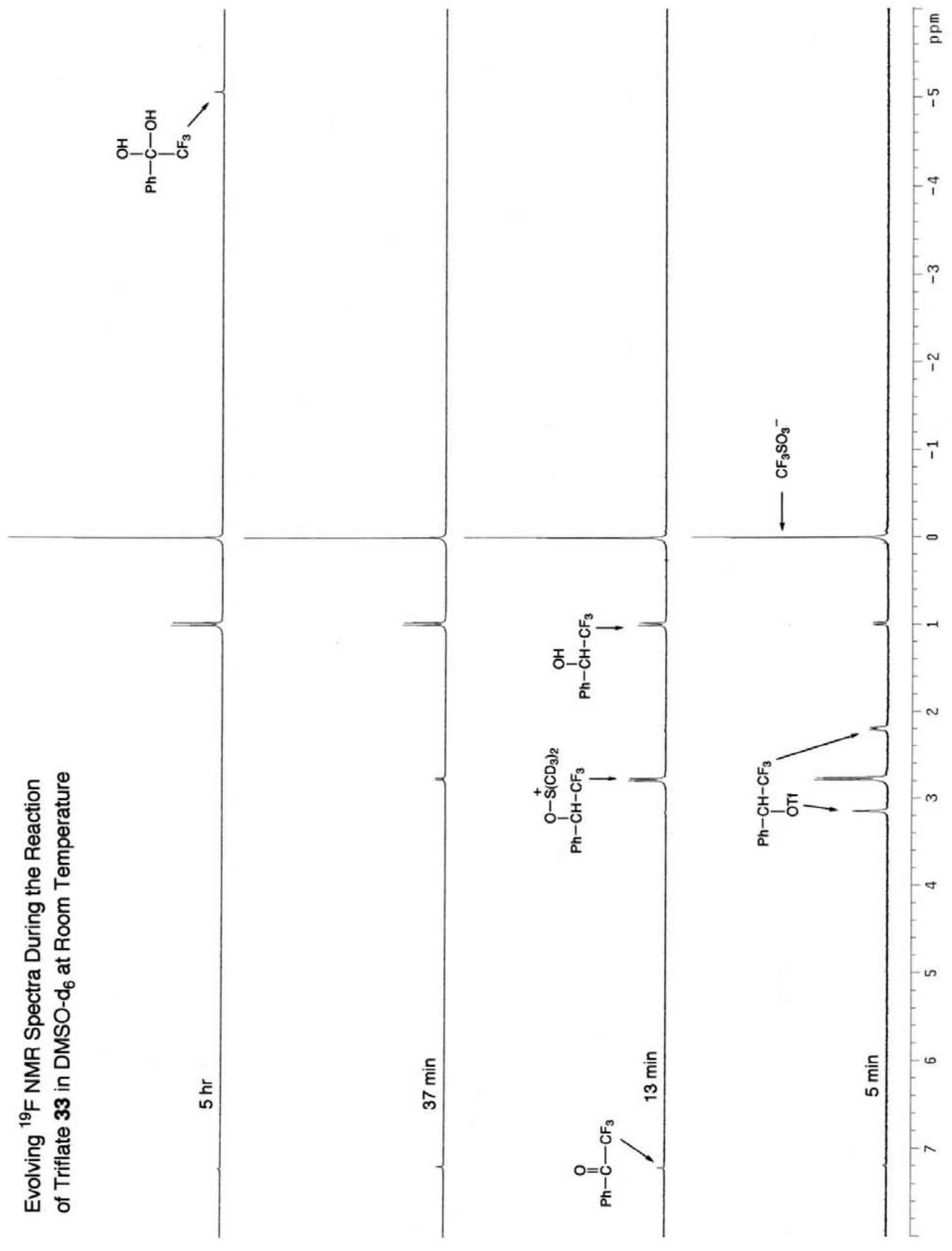

